\title{
PERJAMUAN KUDUS DAN IDUL ADHA SEBAGAI DASAR TEOLOGI BAGI REKONSILIASI HUBUNGAN KRISTEN DAN ISLAM DI INDONESIA
}

\author{
Christian Siregar \\ Character Building Development Center (CBDC), BINUS University \\ Jln. Kemanggisan Ilir III No. 45, Kemanggisan - Palmerah, Jakarta 11480 \\ martahidame@yahoo.com
}

\begin{abstract}
This paper is intended as an alternative to solving the problem of conflict that often occurs between the two religious missions in Indonesia, Islam and Christianity. The solution offered is to reflect on and interpret the meaning of two great celebrations in the tradition of Islam and Christianity, Eid ul-Adha and the Lord's Supper, which is shared with others. A theological review is required to complete a philosophy of our country, Pancasila, so that the reconciliation which is basicly desired by all religions in Indonesia can be realized with sustainably. Religious-Islam and Christian-side by side can build a more prosperity dan peaceful life. Discussion in this paper is based on a review of selected literature which is relevant to the topic and up to date. From the results of the study it can be concluded that forgiveness is a courage act that needed, which can bring about reconciliation among Christians-Islam by re-purposing the celebration of Holy Communion and Eid alAdha.
\end{abstract}

Keywords: lord's supper, eid ul-adha, theology, reconciliation, christianity-islam

\begin{abstract}
ABSTRAK
Makalah ini dimaksud sebagai alternatif pemecahan masalah konflik yang kerap terjadi di antara dua kubu agama misi di Indonesia, yakni Islam dan Kristen. Solusi yang ditawarkan adalah dengan merefleksikan dan memaknai kembali makna asasi dua hajatan besar dalam tradisi Islam dan Kristen, Idul Adha dan Perjamuan Kudus, yakni berbagi kepada sesama. Tinjauan teologis diperlukan untuk melengkapi falsafah negara kita, Pancasila, agar rekonsiliasi yang hakikinya menjadi dambaan semua umat beragama di Indonesia dapat diwujudkan dengan lestari. Umat beragama-Islam dan Kristen-dapat bersanding untuk membangun kehidupan yang lebih damai dan sejahtera. Pembahasan makalah ini dilakukan berdasarkan kajian sejumlah literatur terpilih yang relevan dengan topik dan up to date. Dari hasil kajian dapat disimpulkan bahwa pemaafan adalah tindakan berani yang dibutuhkan, yang dapat mewujudkan rekonsiliasi di kalangan KristenIslam berdasarkan pemaknaan kembali perayaan Perjamuan Kudus dan Idul Adha.
\end{abstract}

Kata kunci: perjamuan kudus, idul adha, teologi, rekonsiliasi, kristen-islam 


\section{PENDAHULUAN}

Sejarah merekam rivalitas "abadi” antara Kekristenan dan Islam. Tidak jarang umat keduanya terlibat dalam aksi saling bunuh. Burke (2010) menyebutkan, para ksatria Kristen dari Eropa berdatangan ke Israel/Palestina dan merebut kembali kota Yerusalem yang sebelumnya ditaklukkan oleh Kalifah Umar (638) dari pasukan Arab. Berbeda dengan Umar yang menghormati orang Yahudi dan Kristen sehingga tidak membasmi seisi kota, maka para ksatria Kristen yang memakai nama Tentara Salib (The Crusader) telah bertindak kejam dengan membantai hampir seisi kota, baik Yahudi maupun Muslim. Tindakan brutal itu dan simbol Tentara Salib telah memancing amarah di kalangan orang Muslim. Di bawah pimpinan Saladin (Salahudin) pasukan Muslim berperang dengan para ksatria Kristen, yang berakhir dengan kekalahan Tentara Salib di Galilea (1187). Perang Salib yang berlangsung selama lebih kurang seabad (1099-1187) — dan di kalangan umat Islam khususnya sampai sekarang masih meninggalkan luka batin, mengingat fanatisme dan kekejaman Tentara Salibhanyalah salah satu dari segudang peristiwa berdarah tersebut. Motifnya memang tidak selalu soal ketegangan klaim kebenaran dan keselamatan religius. Acap kali kepentingan ekonomi dan politik ikut menorehkan warna kelam dalam sejarah relasi ini. Dalam keadaan ini, haruslah diakui bahwa tidak mudah untuk memilah motif-motif tersebut.

Relasi kedua agama misi ini di Indonesia tidak lebih baik dibandingkan dengan di daratandaratan lainnya. Dihapusnya tujuh kata kontroversial dalam Piagam Jakarta dinilai oleh beberapa kalangan sebagai titik kejatuhan Islam dan kemenangan Kristen dalam pertempuran mengenai dasar negara ini. Sebelum peristiwa itu, yaitu pada masa kolonialisasi asing, pemerintah cenderung menganakemaskan kelompok Kristen. Hal ini terlihat dari tindakan pemberian berbagai hak istimewa dan bantuan ini-itu berjumlah besar kepada berbagai lembaga yang digawangi oleh agama ini. Pada masa pendudukan Jepang, Islam yang berada di atas angin, sedangkan Kristen ditindas sedemikian rupa.

Berdasarkan data sejarah di atas, relasi Kristen dan Islam memerlukan rekonsiliasi. Kenapa? Menurut penulis, Indonesia tidak akan naik tingkat dari level negara berkembang menuju level negara maju tanpa partisipasi aktif setiap elemen masyarakatnya. Perseteruan antar elemen tentulah menghambat laju pembangunan negara ini. Memang itu hanyalah satu alasannya. Namun, yang terutama, mimpi hidup damai dalam perbedaan tidak akan pernah terwujud bila masalah ini tidak segera diselesaikan.

Pancasila memang diakui sebagai dasar kehidupan bersama bagi setiap elemen yang berbeda. Keberadaannya dianggap dapat meredakan konflik berkepanjangan ini. Sayangnya, setelah sekian tahun Pancasila hadir, tetapi relasi ini belum kunjung membaik. Tampaknya Pancasila sebagai platform politik perlu didampingi oleh berbagai platform lain, misalnya teologi, yang memiliki semangat rekonsiliasi.

Sakramen Perjamuan Kudus dalam Kekristenan dan Hari Raya Idul Adha dalam Islam merupakan dua warisan teologi yang memiliki semangat itu. Makalah singkat ini akan berusaha menggali makna rekonsiliatif dari kedua warisan teologi tersebut. Bila memang ada, mungkinkah umat Kristen ikut serta dalam perayaan Idul Adha atau sebaliknya? Jika mungkin, keikutsertaan macam apa yang dapat dilakukan? Pertanyaan-pertanyaan ini akan penulis coba jawab dalam tulisan ini. Harapan penulis adalah, jika pun ada makna semacam itu, semoga cukup mampu untuk menjadi dasar bagi perdamaian di antara kedua agama. Apa yang dimimpikan penulis hanyalah sebuah negara dan bangsa bernama Indonesia yang damai, adil, dan sejahtera sekalipun hidup dalam keberagaman relijius dan kultural. 


\section{METODE}

Pembahasan makalah ini dilakukan berdasarkan kajian sejumlah literatur terpilih yang relevan dengan topik dan up to date. Literatur yang dipergunakan adalah bahan-bahan terpilih yang mengacu kepada kedua komunitas umat beragama yang dibahas, baik dari teks-teks kitab suci Al-Quran (Islam) dan Alkitab (Kristen). Di samping menggunakan teks-teks (kutipan) dari ayat-ayat kitab suci kedua agama, penulis juga menggunakan kajian-kajian yang terkait dengan pokok bahasan dari literaturliteratur ilmiah sebagai pendukung yakni: buku, jurnal, media surat kabar dan situs internet.

Langkah-langkah penelitian adalah sebagai berikut: Mengamati perkembangan relasi sosial Islam-Kristen terkini, meninjau relasi tersebut dari perspektif perayaan Idul Adha (Islam) dan Perjamuan Kudus (Kristen); meninjau dari pemaknaan teologis-etisnya, menemukan titik-titik pertemuan (kesamaan)-nya, mendukung nilai-nilai positif dari penemuan titik-titik pertemuan itu dengan referensi-referensi yang ada (dukungan teks-teks kitab suci dan literatur-literatur lainnya), merelevansikan hasil penemuan itu secara aplikatif dengan maksud dan tujuan penulisan dalam kerangka berpikir analisis-reflektif.

\section{HASIL DAN PEMBAHASAN}

\section{Makna Idul Adha, Perjamuan Kudus dan Semangat Rekonsiliasi}

\section{Idul Adha: Bukan Sekadar Berkurban}

Idul Adha selalu menyuguhkan pemandangan yang sama tiap tahunnya. Sederet bangunan kayu sederhana yang difungsikan sebagai kandang kambing dan sapi didirikan di pinggir jalan raya. Tidak sedikit pedagang hewan kurban yang menjajakan dagangannya di media massa dan jejaring sosial dunia maya. Cara yang jauh lebih modern dan praktis ini menawarkan kemudahan berkurban bagi para calon pembeli. Mereka menjanjikan hewan kurban yang telah dibeli akan segera diberikan kepada pihak yang berhak menerimanya.

Allah SWT menganjurkan umat-Nya untuk berkurban. QS Al-Hajj ayat 34 berbunyi, "Dan bagi tiap-tiap umat telah Kami syariatkan penyembelihan (kurban), supaya mereka menyebut nama Allah terhadap binatang ternak yang telah diberikan Allah kepada mereka, maka Ilahmu ialah Ilah Yang Maha Esa, karena itu berserah dirilah kamu kepada-Nya. Dan berilah kabar gembira kepada orang-orang yang tunduk patuh (kepada Allãh)." Ayat tersebut perlu disandingkan dengan ayat ke-37 dari surat tersebut yang menjelaskan bahwa bukanlah daging dan darah ternak kurban yang diridhai oleh Allah SWT, melainkan ketakwaan manusia. Dengan demikian, bagi umat Islam, kurban merupakan sesuatu yang penting karena merupakan bagian dari syari'ah agama, tanda ketaatan pada tauhid, dan sarana untuk mendekatkan diri kepada Sang Khalik (Mutaqin, 2012).

Selain dalam Al-Quran tersebut, kurban pun dibicarakan oleh Nabi Muhammad SAW dalam Hadist. Ia mengatakan bahwa kurban itu, bagi tuannya dengan setiap bulunya, adalah kebajikan. Ahmad Sahidah, seorang dosen filsafat dan etika Universitas Utara Malaysia, menuliskan kajian dan penafsiran yang menarik dalam artikelnya yang berjudul Metafora Kurban Kambing. Ia memandang bahwa Hadist tersebut memang menjanjikan pahala bagi para pekurban. Namun, semangat berbagi kepada sesama-lah yang hendak diajarkan oleh Nabi kepada umat Islam, bukan anjuran untuk menjadikan pahala sebagai orientasi pribadi. "Ia adalah kiasan tentang betapa banyaknya kebaikan yang dapat dimanfaatkan oleh orang yang memerlukan" (Sahidah, 2012). Dengan demikian, kurban seharusnya dapat menjadi salah satu alat untuk menciptakan kesejahteraan sosial. 
Selanjutnya, Sahidah menggarisbawahi kisah pengurbanan yang dilakukan Nabi Ibrahim. Dalam kisah tersebut, sang nabi menunjukkan ketaatan luar biasa kepada Allah SWT dan perintahNya. Ia tidak segan untuk mengurbankan buah hatinya, yaitu Ismail, demi Sang Khalik. Akhirnya, Allah menggantikan Ismail dengan seekor hewan ternak setelah melihat kebulatan hati nabi. Berdasarkan kisah tersebut, Sahidah menyimpulkan bahwa ketaatan manusia kepada Allah tidak boleh mengorbankan sesama (Sahidah, 2012).

Ayat-ayat Al-Quran dan Hadist Nabi di atas merupakan ajaran-ajaran Islam yang mengandung dimensi hablum minallah dan dimensi hablum minannas. Segi relasi dengan Allah SWT terwujud dari kerinduan manusia untuk mendekatkan diri kepada-Nya melalui berbagai bentuk ibadah, yaitu haji, shalat, dan kurban. Segi yang lain, yaitu relasi dengan sesama manusia, terejawantah dalam praktik ibadah kurban.

\begin{abstract}
"Kurban pada dasarnya bagai keping mata uang, yaitu antara pengaplikasian cinta hamba terhadap Rabb-nya dan juga pengaplikasian cinta hamba antara sesamanya. Hubungan antara hamba dengan Allah adalah dengan pengorbanannya menjalankan perintah-Nya, sedangkan hubungan antara hamba dengan sesama manusia adalah dengan membagi-bagikan daging kurban pada yang membutuhkan. Keduanya tak bisa dipisahkan. Itu sebabnya dalam salah satu ayat al-Quran disebutkan bahwa perintah kurban disandingkan dengan shalat" (Mizan, 2012).
\end{abstract}

Lantas, siapakah 'sesama' menurut Islam? Apakah para pemeluk agama selain Islam dipandang sebagai sesama? Ghazali (2009) berpendapat bahwa keberagaman agama merupakan kehendak Allah SWT. Sang Pencipta mengizinkan manusia hidup dalam kondisi itu dengan tujuan manusia dapat saling mengenal dan menghargai eksistensi masing-masing tanpa niat untuk saling memusuhi dan menghancurkan.

Keberagaman agama diperkenankan oleh Allah bukan dalam rangka membenarkan diskriminasi umat Islam, melainkan agar manusia berlomba-lomba berbuah kebaikan. "Agama bukan tujuan (ghayat), melainkan sarana (wasilat) yang mengantarkan para penganutnya menuju Tuhan. Kemuliaan manusia di hadapan Tuhan dinilai berdasarkan kebaikan dan ketulusannya dalam beramal." (Ghazali, 2009). Dengan demikian, bagi Islam, pihak yang dimaksudkan dengan kata 'sesama' adalah manusia lain yang sama dalam hakikatnya sebagai manusia. Atribut agama, suku, ras, dan golongan yang melekat pada diri tidak menghalangi Islam memandang manusia sebagaimana adanya.

Semangat rekonsiliasi ibadah kurban terwujud dalam kegiatan membagikan sekian gram berat daging ternak yang telah disembelih kepada sesama, yaitu kaum papa, tanpa pandang bulu. Peristiwa itu merupakan upaya menciptakan perdamaian antara si kaya dan si miskin yang hidup terpisah oleh jurang kesenjangan sosial. Selama tiga hari si pemberi diajarkan untuk mengingat bahwa terdapat hak si penerima dalam sebagian hartanya. Tujuannya adalah sepanjang hidupnya atau setidaknya selama setahun hingga perayaan Idul Adha berikutnya tiba, si kaya ingat akan tanggung jawab untuk ikut memelihara kehidupan si miskin. Dengan begitu, ia akan layak disebut sebagai seorang penganut Islam yang sejati karena telah berpartsipasi merahmati alam semesta.

\title{
Menjadi Peringatan Akan Aku: Mengingat dalam Perjamuan Kudus
}

Mengingat merupakan inti dari Perjamuan Kudus. Dalam surat kepada jemaat di Korintus, Paulus menulis demikian, “... Tuhan Yesus, pada malam waktu Ia diserahkan, mengambil roti dan sesudah itu Ia mengucap syukur atasnya; Ia memecah-mecahkannya dan berkata: Inilah tubuh-Ku, yang diserahkan bagi kamu; perbuatlah ini menjadi peringatan akan Aku! Demikian juga Ia mengambil cawan, sesudah makan, lalu berkata: Cawan ini adalah perjanjian baru yang dimateraikan oleh darah-Ku; perbuatlah ini, setiap kali kamu meminumnya, menjadi peringatan akan Aku!" (1 Kor. 11: 23-25). Dalam ayat-ayat tersebut, kata anamnesin yang diterjemahkan sebagai 'peringatan akan Aku' diulang beberapa kali untuk mengindikasikan pentingnya tindakan ini. 
Menurut Pakpahan, surat itu sengaja ditulis oleh Paulus untuk mengkritik kebiasaan buruk jemaat Kristen perdana di Korintus. Cara mereka makan dan minum dalam persekutuan tidak berbeda dengan apa yang dilakukan dalam Eranos ( $\rho \alpha v o s:$ yakni perjamuan makan biasa pada tradisi Yunani kuno di mana para tamu masing-masing membawa kontribusi makanan mereka sendiri; jadi tidak ada tuan rumah yang khusus menyediakan hidangan bagi para tamu, red). Anggota yang datang terlebih dahulu selalu menghabiskan makanan dan minuman yang tersedia dengan rakus tanpa menyisihkan bagi mereka yang datang kemudian. Akibatnya adalah sebagian kekenyangan dan mabuk, sedangkan yang lain kelaparan. Selain itu, si kaya pun tidak rela berbagi dengan si miskin (Pakpahan, 2012: 147).

Ketidaksetujuan Paulus atas tindakan jemaat Korintus didasarkan pada konsep mengenai persekutuan. Ia menilai ketamakan dan keegoisan yang mereka tunjukkan akan mencederai semangat komunal. Oleh karena itu, rasul ini memberikan makna Kristiani pada perjamuan kudus dengan menekankan keberadaan Kristus di dalamnya. Jemaat di Korintus diajak untuk mengingat-Nya setiap kali mereka makan dan minum. Orientasi mereka digeser dari self-oriented menuju Christ-oriented.

Apa yang diingat dalam perjamuan kudus oleh umat adalah Kristus dan karya keselamatan yang telah dilakukan-Nya di masa lalu. Kematian-Nya di atas kayu salib terjadi dalam rangka mengampuni dosa-dosa manusia. Setelah peristiwa besar itu, relasi antara Allah dan manusia dipulihkan. Walaupun terjadi di masa lalu, kematian Kristus hadir di masa kini melalui ingatan umat dan berdampak bagi masa depan. Umat menantikan parousia yang akan datang dengan harapan tidak lagi "melihat cermin yang samar" dalam ingatan mereka, melainkan dapat bertemu Kristus muka dengan muka (Pakpahan, 2012)

Lantas, selain dimensi rekonsiliasi vertikal antara Allah dan manusia, adakah dimensi rekonsiliasi sosial di dalam perjamuan kudus? Ya! Perjamuan kudus merupakan suatu tindakan liturgis yang dilakukan secara komunal seperti Kristus melakukannya bersama dengan para murid di masa lalu. Bila ada dari antara umat yang memiliki relasi buruk dengan sesamanya, ia haruslah "meninggalkan persembahan di depan mezbah dan pergilah berdamai dahulu dengan saudaramu, lalu kembali untuk mempersembahkan persembahanmu itu" (bdk. Matius 5: 24).

\section{Semata-mata demi Kebenaran: Mengingat dan Rekonsiliasi}

Indonesia memiliki Monumen Pancasila Sakti di Jakarta yang didirikan sebagai peringatan peristiwa berdarah yang terjadi pada 30 September 1965. Pemerintah Australia mengkhususkan sebuah hari, yaitu $26 \mathrm{Mei}$, untuk mengingat kesalahan pemerintah kolonial pada abad ke-20 atas suku Aborigin sebagai penduduk asli. Sebuah badan bernama Truth and Reconciliation Commission dibentuk oleh pemerintah untuk menemukan kembali kebenaran mengenai tindakan kekerasan yang terjadi pada era apartheid di Afrika Selatan. Tiga fenomena itu menunjukkan bahwa manusia memilih untuk mengingat masa lalu, sekalipun pahit dan menyakitkan, alih-alih melupakannya.

Namun, apakah tindakan mengingat merupakan pilihan yang tepat? Bukankah itu malah membuka luka lama? Lagipula, bukankah akar dari aksi balas dendam adalah ingatan akan peristiwa masa lalu yang kelam? Oleh karena itu, sebagian orang yang berada di posisi korban memilih untuk mengubur luka dan berharap dapat melupakannya seiring waktu berjalan. Kalau pun mereka tetap mengingat, pengalaman-pengalaman buruk di masa lalu hanya dijadikan sebagai alasan logis dan ujung tombak untuk membalas dendam.

Pakpahan berpendapat bahwa tindakan melupakan tidak akan pernah bermuara pada tindakan memaafkan. "For if you totally forget that someone once hurt you, you cannot forgive that person. Forgetting is not permanent. The memory is not eradicated and it can be resurrected" (Pakpahan, 2012). Dengan demikian, tindakan mengingat merupakan langkah awal dalam proses memaafkan kejahatan orang lain. Ini tidak berarti posisi keadilan digantikan oleh tindakan memaafkan. Apa 
jadinya bila kasus pelanggaran HAM, misalnya genosida, lekang oleh waktu tanpa sempat diperkarakan di meja hijau?

Mengingat bukanlah sekadar tindakan menarik kembali peristiwa yang terjadi di masa lampau. Bila hanya demikian, tindakan ini akan bermuara pada aksi balas dendam yang diwarnai kekerasan. Menurut Volf, tindakan mengingat haruslah didasarkan pada kejujuran. Pihak korban hanya diperkenankan mengingat apa yang benar-benar terjadi berdasarkan pengalaman mereka dengan kebenaran sebagai tujuan yang hendak dicapai. "Be truthful in telling what you remember no less than in telling what you experience or intend to do." (Volf, 2006a). Dengan demikian, mengingat harus dilakukan demi dan dalam kerangka menemukan kebenaran semata-mata.

Langkah selanjutnya yang harus dilakukan dalam proses rekonsiliasi adalah merangkul. Volf berpendapat bahwa pihak pelaku dan korban yang terlibat dalam perseteruan haruslah membuat ruang dalam diri masing-masing sebagai tempat bagi sudut pandang yang lain. Sudut pandang dari kedua pihak yang hampir pasti berbeda akan bertemu dan berdialog dalam ruangan tersebut (Pakpahan, 2012). Dengan begitu, tidak akan ada ingatan dari salah satu pihak yang lebih mendominasi dan kemungkinan memanipulasi diperkecil.

Bila kedua langkah tersebut telah dilewati dengan baik, memaafkan dan bertobat baru dapat dilakukan. Dengan mengutip Volf, Pakpahan berpendapat bahwa memaafkan merupakan suatu alat ampuh yang dapat digunakan untuk memutus lingkaran balas dendam. Walaupun demikian, tindakan ini tidak menggantikan keadilan. Memaafkan dipahami sebagai tindakan pihak korban dalam mengiyakan pengalaman masa lalu buruk yang telah menimpa mereka sekaligus wujud dari keinginan untuk melepaskan pihak pelaku dari rasa bersalah dan hukuman (Pakpahan, 2012).

Lantas, apa bagian pihak pelaku? Tindakan yang harus dilakukan oleh pihak tersebut adalah bertobat. Pihak pelaku hanya mungkin bertobat bila telah menyadari kesalahannya dan dimaafkan oleh pihak korban. Volf mengatakan bahwa tindakan memaafkan memang tidak menyebabkan adanya pertobatan, tetapi ini memungkinkan pihak pelaku untuk bertobat (Volf, 2006b).

Langkah-langkah yang telah di atas merupakan rangkaian proses rekonsiliasi. Setelah semua itu dilakukan rekonsiliasi hubungan akan tercipta. Tanda-tandanya adalah pihak korban mengalami keamanan dan kehidupannya dipulihkan. Di lain sisi, pihak pelaku mengakui kesalahannya, menerima ganjaran, dan mengalami transformasi kehidupan.

\section{SIMPULAN}

Hubungan antara Islam dan Kristen amatlah memprihatinkan. Kedua umat dari agama misi ini sering kali terlibat dalam pertempuran berdarah. Penyebabnya tidak hanya soal pendakuan radikal atas kebenaran dan keselamatan, tetapi juga diperparah oleh kepentingan-kepentingan tertentu yang demonis. Pada saat itulah, kita tidak mudah membedakan yang mana motif agama dan mana yang dorongan nafsu duniawi. Yang terlihatnya hanyalah dua kubu manusia yang mengacungkan senjata kepada yang lain sambil meneriakan nama Tuhan masing-masing seolah aksi itu diperkenankan-Nya.

Demi kedamaian hidup berbangsa dan bernegara dan atas nama perjuangan menuju masa depan yang lebih baik, relasi problematis relasi Kristen dan Islam harus segera diselesaikan. Pancasila sebagai ideologi bangsa perlu didampingi oleh teologi rekonsiliatif masing-masing agama untuk mendamaikan keduanya. Islam memiliki teologi seperti itu dalam kurban hewan yang dilakukan ketika Idul Adha, sedangkan Kristen memilikinya dalam perjamuan kudus. 
Kesamaan kedua ritual keagamaan ini adalah keduanya memberikan tempat yang penting bagi tindakan mengingat. Dalam ritual kurban, umat Islam diajak untuk mengingat peristiwa pengurbanan Ismail yang terjadi di masa lampau. Melalui ingatan itu, mereka diajarkan bahwa ketaatan kepada Allah tidak boleh mengorbankan sesama. Dengan demikian, hubungan vertikal terjalin tanpa melupakan relasi horizontal. Melalui perjamuan kudus, umat Kristen diajak untuk mengingat kematian Kristus di kayu salib yang mendamaikan Allah dan manusia. Ritual komunal ini menuntut umat yang berpartisipasi di dalamnya untuk hidup dalam kedamaian dengan sesamanya.

Umat Kristen tidak perlu lagi memandang Idul Adha dan pelaksanaan ritual kurban sebagai pemborosan dan tidak berdampak etis apapun karena apa yang diajarkan melaluinya sangatlah mulia. Sebaliknya, umat dapat berpartisipasi dengan para pemeluk Islam dalam perayaan ini dengan berbagai cara yang positif karena yang diusahakan adalah keadilan sosial; kesenjangan antara si kaya dan si miskin yang sedang dikikis. Di lain sisi, umat Islam pun perlu berpartisipasi dalam perjamuan kudus hingga batas-batas tertentu yang diperkenankan oleh agama mereka tanpa kehilangan pemahaman akan semangat rekonsiliatif diajarkan melaluinya. Sebagai penutup, penulis semakin berani berharap rekonsiliasi Kristen dan Islam tidaklah hanya sebatas impian. Semoga penulis tidaklah sendirian dalam berharap akan masa depan Indonesia yang gemilang itu; suatu keadaan semua hal menjadi baru dan baik seperti baru saja diciptakan.

\section{DAFTAR PUSTAKA}

Burke, G. M. (2010). Palestina Milik Siapa? Jakarta: BPK Gunung Mulia.

Ghazali, A. M. (2009). Argumen Pluralisme Agama: Membangun Toleransi Berbasis Al-Quran. Depok: KataKita.

Mizan. 25 Oktober (2012). Shalat dan Kurban: Dua Keping Mata Uang "Hablum Minallah" dan "Hablum Minannas". Diakses 7 Desember 2012, dari http://www.mizan.com/news_det/shalat-dan-kurban-dua-keping-mata-uang-hablumminallah-dan-hablum-minannas.html.

Mutaqin, A. 31 Oktober (2012). Idul Qurban: Kemurnian Tauhid dan Kesalehan Sosial. Diakses 7 Desember 2012, dari http://www.muhammadiyahlimo.wordpress.com/2012/10/31/idulqurban-kemurnian-tauhid-dan-kesalehan-sosial/

Pakpahan, B. J. (2012). God Remembers: Towards a Theology of Remembrance as a basis of Reconciliation in Communal Conflict. Amsterdam: VU University Press.

Sahidah, A. 25 Oktober (2012). Metafora Kambing Kurban. Koran Tempo. Jakarta: PT Tempo Inti Media Tbk.

Volf, M. (2006a). Free of Charge: Giving and Forgiving in a Culture Stripped of Grace. Gran Rapids: Zondervan.

(2006b). The End of Memory: Remembering Rightly in a Violent World. William B. Eerdmans: Gran Rapids. 